\title{
Experimental characterization of thermo-oxidation induced shrinkage and damage onset in polymer matrix composites at high temperature
}

\author{
D. -Q. Vu ${ }^{1, a}$, M. Gigliotti ${ }^{1}$, M.-C. Lafarie ${ }^{1}$, and J. -C. Grandidier ${ }^{1}$ \\ ${ }^{1}$ Institut Pprime, CNRS - ENSMA - Université de Poitiers, UPR 3346, Département Physique et \\ Mécanique des Matériaux, ENSMA - Téléport 2 - 1, avenue Clément Ader, BP 40109 - F86961 \\ FUTUROSCOPE CHASSENEUIL Cedex, FRANCE
}

\begin{abstract}
This paper focuses on the experimental characterization of thermo-oxidation in carbon fibre reinforced polymers (CFRP) exposed to "high" temperatures (up to $150^{\circ} \mathrm{C}$ ) and "high" oxygen pressures (up to 5 bars). Thermo-oxidation induces matrix shrinkage and damage in CFRP. In this study these are both investigated at room temperature by means of confocal interferometric microscopy (CIM) and scanning electron microscopy (SEM).
\end{abstract}

\section{Introduction}

In the aerospace industry, widespread use is made of continuous CFRP laminates, since they possess very interesting specific mechanical properties. Nowadays, such materials are used in structural parts subjected to rather severe thermal conditions. For instance, for composite materials exposed to oxidative environments at high temperatures $\left(>120^{\circ} \mathrm{C}\right)$, oxidation reaction/diffusion phenomena take place within the polymer material and threaten the integrity of the structure. Thus, an increased demand for long lifetime requires better understanding of the oxidation processes and their consequences in terms of mechanical degradation. Some research has been carried out on the chemical aspects of the oxidation process [1] and on its effects on the material mechanical behaviour [2-4]. Thermo-oxidation is responsible for departure of volatile species and macromolecular chain scission in polymer matrix leading to chemical shrinkage strains and changes in mechanical and fracture properties of the neat resin [5]. In the presence of thermomechanical solicitations this gives rise to localized micromechanical residual stresses in the composite material which can induce damage at fibre/matrix interfaces and promote intralaminar microcracking. Damage can then create additional permeation paths for oxygen deep into the composite increasing the oxidation rate. The characterization of thermo oxidation induced matrix shrinkage is very important. In this work, we will focus on quantifying the matrix shrinkage and the onset of fibre-matrix debonding.

\footnotetext{
a e-mail : dinhquy.vu@1mpm.ensma.fr
} 


\section{Experimental setup}

\subsection{Sample preparation and aging}

The samples of dimension $20 \mathrm{~mm} \times 15 \mathrm{~mm} \times 10 \mathrm{~mm}$ were cut out from a unidirectional $[0]_{40}$ IM7/9772 composite plates received from EADS IW and were polished automatically by an optimized procedure to minimize the impact of polishing (see fig. 1). These samples are then subjected to isothermal aging tests at $150^{\circ} \mathrm{C}$ under atmospheric air and oxygen pressure in a climatic chamber which can operate at high temperatures (up to $200^{\circ} \mathrm{C}$ ), high pressures (up to 10 bars) and in the presence of mechanical loading [5].

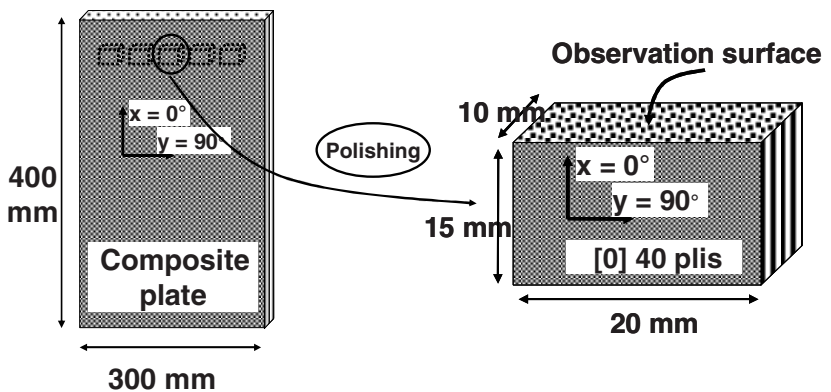

Fig. 1. Material and sample

\subsection{Experimental characterization}

\subsubsection{Matrix shrinkage quantification by CIM}

We use confocal interferometric microscopy (TALYSURF CCI 6000) to characterize the polished surface of sample before and after aging. This is a 3D non-contact measurement with very high vertical resolution $(0.01 \mathrm{~nm})$. The specification of the method corresponding to 50x lens is listed in table 1 .

Table 1. Specification of TALYSURF CCI 6000 corresponding to 50x lens

\begin{tabular}{|c|c|c|c|}
\hline $\begin{array}{c}\text { Vertical } \\
\text { resolution }(\mu \mathrm{m})\end{array}$ & $\begin{array}{c}\text { Lateral } \\
\text { resolution }(\boldsymbol{\mu m})\end{array}$ & $\begin{array}{c}\text { Maximum } \\
\text { slope }(\text { degree })\end{array}$ & $\begin{array}{c}\text { Measurement } \\
\text { area }(\boldsymbol{\mu m})\end{array}$ \\
\hline $10^{-5}$ & 0.35 & 27.7 & $360 \times 360$ \\
\hline
\end{tabular}

In this work, we characterize the matrix shrinkage induced by thermo-oxidation by measuring the matrix displacement profile between two fibres. The form and the maximal depth of the profile are both analysed. By this method, the maximal slope measurable is $27^{\circ}$ (in the 50x lens case). So, all points with a slope greater than $27^{\circ}$ are represented by non-measured points. Figure 2 shows an example of a matrix profile between two fibres extracted by CIM. 


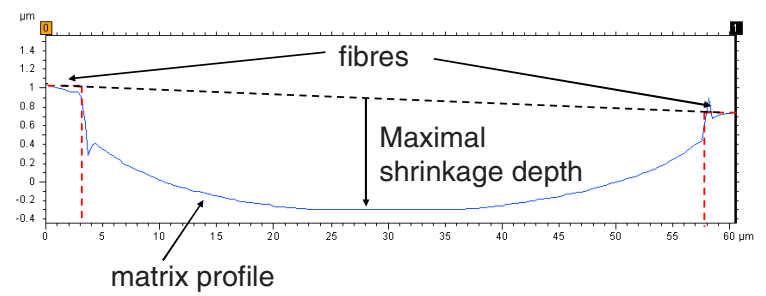

Fig. 2. Matrix profile between two fibres extracted by CIM.

\subsubsection{Damage observations by SEM}

In this work, the surface of the samples was observed by (JEOL JSM-6400). While the carbon fibre is conducive, the epoxy matrix is a nonconductive material. To be observable by SEM, the sample surface needs to be coated with an ultrathin coating of electrically-conducting material, gold in our case. We will focus on the observation of matrix shrinkage and fibre-matrix debonding. The sample is tilted $45^{\circ}$ in order to better visualise matrix shrinkage and fibre-matrix debonding.

\section{Results and discussions}

\subsection{Initial state: polished surface}

Firstly, to better understand the effects of thermo oxidation on the composite, it is necessary to characterize the initial state of the sample surface before aging, the polished surface. This state will be lately compared to the oxidized state of the sample surface. Figure 3 presents the CIM quantification of maximal matrix shrinkage depth (a) and the SEM observation of the sample polished surface (initial state, before aging) (b).

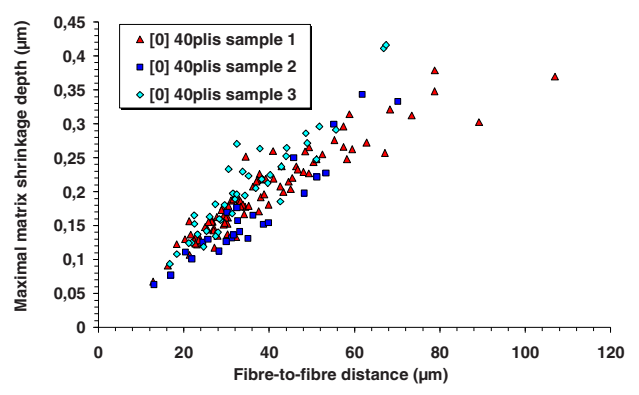

(a)

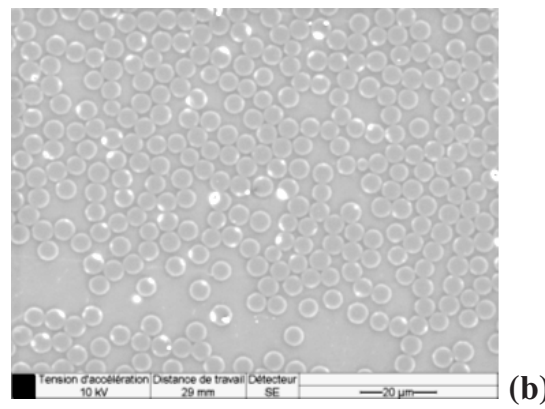

Fig. 3. CIM quantification of the maximal matrix shrinkage depth (a) and SEM observation of the sample polished surface (initial state, before aging) (b).

The measurements were performed on three different samples which were polished by the same procedure. The results shown in fig. 3 confirm the reproducibility of CIM measurements. It is shown that maximal matrix shrinkage depth increases with the fibre-to-fibre distance and its level is about $0.5 \mu \mathrm{m}$. The corresponding SEM image shows that there is no damage on the polished surface of the sample at the initial state.

\subsection{Aging under atmospheric air}


Two different aging tests at $150^{\circ} \mathrm{C}$ under atmospheric air were conducted in the climatic chamber during: $192 \mathrm{~h}$ and $1000 \mathrm{~h}$.

\subsubsection{CIM measurement}

Figure 4 shows the evolution of the maximal matrix shrinkage depth as a function of the fibre-tofibre distance in the composite sample aged $192 \mathrm{~h}$ and $1000 \mathrm{~h}$ under atmospheric air at $150^{\circ} \mathrm{C}$.
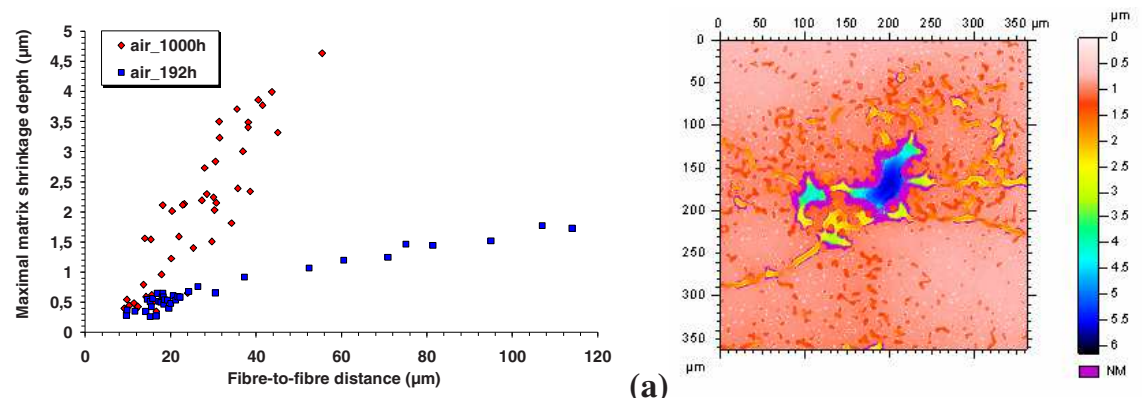

(b)

Fig. 4. a) Evolution of maximal matrix shrinkage depth as a function of the fibre-to-fibre distance in the composite sample isothermally aged at $150^{\circ} \mathrm{C}$ under atmospheric air $192 \mathrm{~h}$ and $1000 \mathrm{~h}$ and CIM

topography of $1000 \mathrm{~h}$ aged sample.

It is shown that the shrinkage level increases with increasing fibre-to-fibre distance and with aging time. The maximal depth is about $2 \mu \mathrm{m}$ and $5 \mu \mathrm{m}$ in the $192 \mathrm{~h}$ and $1000 \mathrm{~h}$ aged samples respectively. The CIM topographies demonstrate that there are many non-measured points in the $1000 \mathrm{~h}$ aged sample which do not exist in $192 \mathrm{~h}$ aged sample. SEM observations are needed to clarify the nature of these non-measured points.

\subsubsection{Damage observations by SEM}

Figure 5 shows SEM observations of two samples aged at $150^{\circ} \mathrm{C}$ under atmospheric air during: $192 \mathrm{~h}$ (a) and 1000h (b).
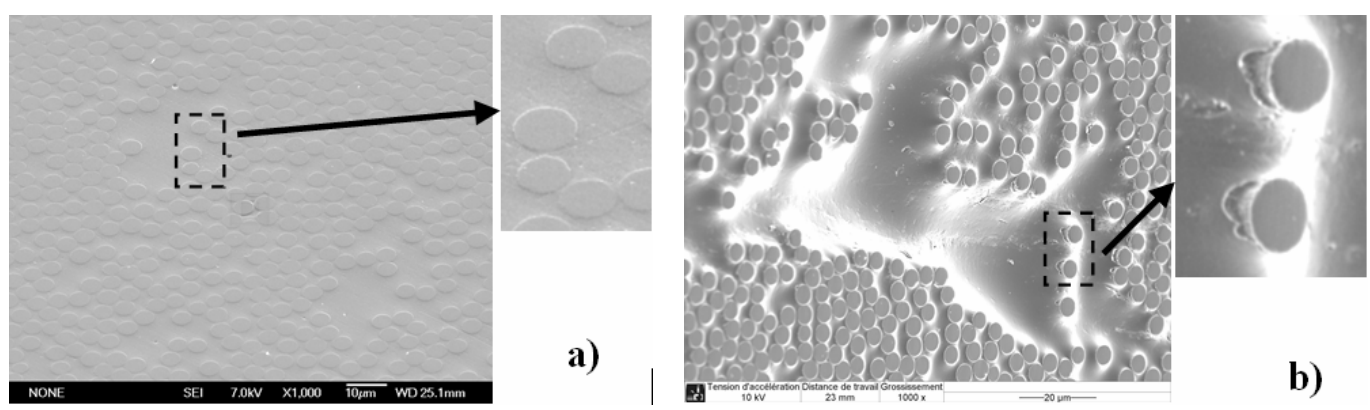

Fig. 5. SEM observations $\left(45^{\circ}\right.$ tilted) of samples isothermally aged at $150^{\circ} \mathrm{C}$ under atmospheric air:

a) $192 \mathrm{~h}$ and b) $1000 \mathrm{~h}$

No fibre-matrix debonding is visible in the 192h aged sample and the shrinkage level in this sample is low as shown by CIM measurement (Fig. 4). On the contrary, in the $1000 \mathrm{~h}$ aged sample, the shrinkage level is very high and fibre-matrix debonding is also visible.

\subsection{Aging under oxygen pressure}


The aging tests under oxygen pressure were carried out in order to accelerate the effects of thermo oxidation on the composite sample. There are very few studies in the literature on accelerated testing by oxygen pressure. In this work, we will study the effect of oxygen pressure on thermo-oxidation induced shrinkage and on the onset of fibre-matrix debonding. In order to capture the onset of the fibre-matrix debonding on a unique sample, interrupted tests were carried out.

\subsubsection{CIM measurements}

Figure 6 shows the evolution of the maximal matrix shrinkage depth as a function of fibre-to-fibre distance in samples aged under 1.7 bars and 5 bars oxygen during different times: $5 \mathrm{~h}, 10 \mathrm{~h}, 20 \mathrm{~h}, 49 \mathrm{~h}$.
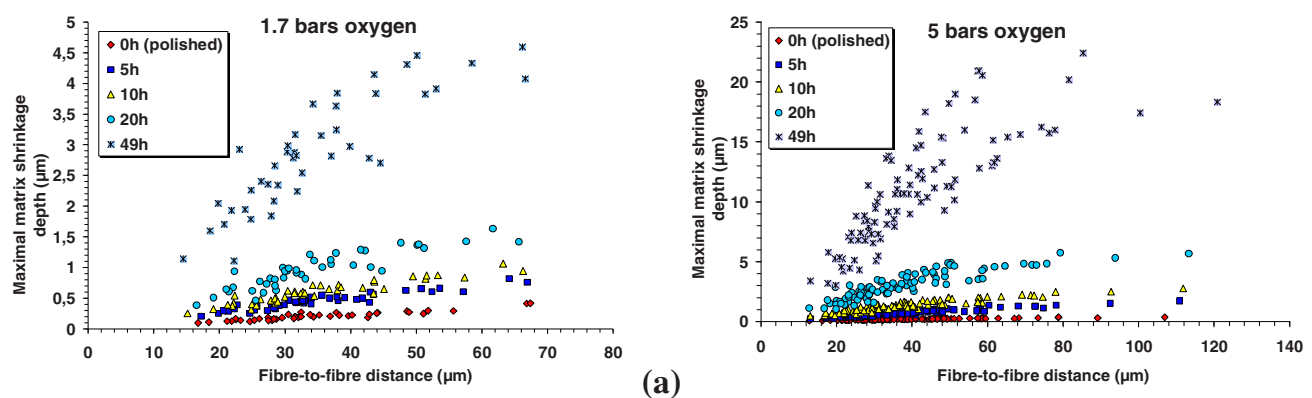

Fig. 6. CIM measurements on samples aged isothermally at $150^{\circ} \mathrm{C}$ under 1.7 bars and 5 bars of oxygen: $5 \mathrm{~h}, 10 \mathrm{~h}, 20 \mathrm{~h}, 49 \mathrm{~h}$

The qualitative shape of these curves is similar. The maximal matrix shrinkage depth increases with the fibre-to-fibre distance and for a given distance it increases with aging time. For the same fibre-tofibre distance and aging time, the maximal matrix shrinkage depth in 5 bars aged sample is much greater than that in 1.7 bars aged sample. For example for 49 hours aging time and $50 \mu \mathrm{m}$ fibre-tofibre distance the maximal shrinkage depth is about $4.5 \mu \mathrm{m}$ and $18 \mu \mathrm{m}$ in 1.7 bars and 5 bars aged sample respectively. It is noted that the dispersion of the CIM measurements is very important. These remarks can be related to the fact that the measurements were performed on different fibre configurations. Figure 7 shows the evolutions of the maximal matrix shrinkage depth in three configurations with the same fibre-to-fibre distance $40 \mu \mathrm{m}$ as a function of aging time in samples aged under 1.7 bars. For each configuration, CIM measurements were performed at the same location (following the same path) at different aging times. The difference of shrinkage levels is significant and increases with aging time. This demonstrates that the dispersion is due to the difference in the configuration arrangement, for a same fibre-to-fibre distance.
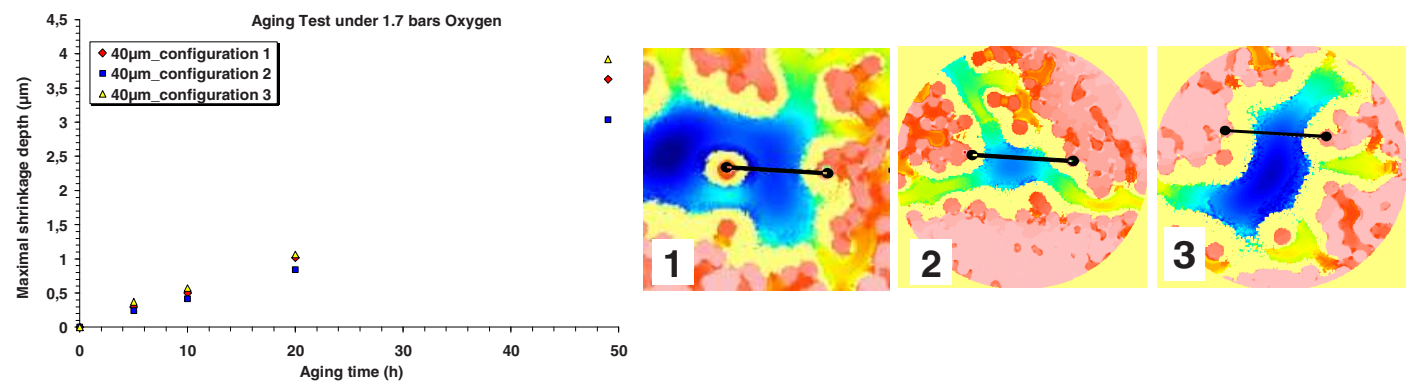

Fig. 7. Evolution of maximal matrix shrinkage depth at sample aged under 1.7 bars oxygen as a function of aging time corresponding to $40 \mu \mathrm{m}$ fibre-to-fibre distance in different fibre configurations 


\subsubsection{SEM observations}

Figure 8 shows SEM observations on two samples isothermally aged at $150^{\circ} \mathrm{C}$ under 5 bars oxygen during $20 \mathrm{~h}$ and $49 \mathrm{~h}$. We can observe that the shrinkage level the $49 \mathrm{~h}$ aged sample is greater than that the $20 \mathrm{~h}$ aged sample. In the $49 \mathrm{~h}$ aged sample, the fibre-matrix debonding is very important corresponding to high matrix shrinkage levels. We can see some naked fibres rising from the matrix. In contrast, in the $20 \mathrm{~h}$ aged sample, there is some fibre-matrix debonding at its onset only observable at high magnification. Other SEM observations on 5 bars and 1.7 bars aged sample during different aging time demonstrate that $20 \mathrm{~h}$ and $49 \mathrm{~h}$ is the time of the onset of fibre-matrix debonding in the 5 bars and 1.7 bars aged samples respectively.
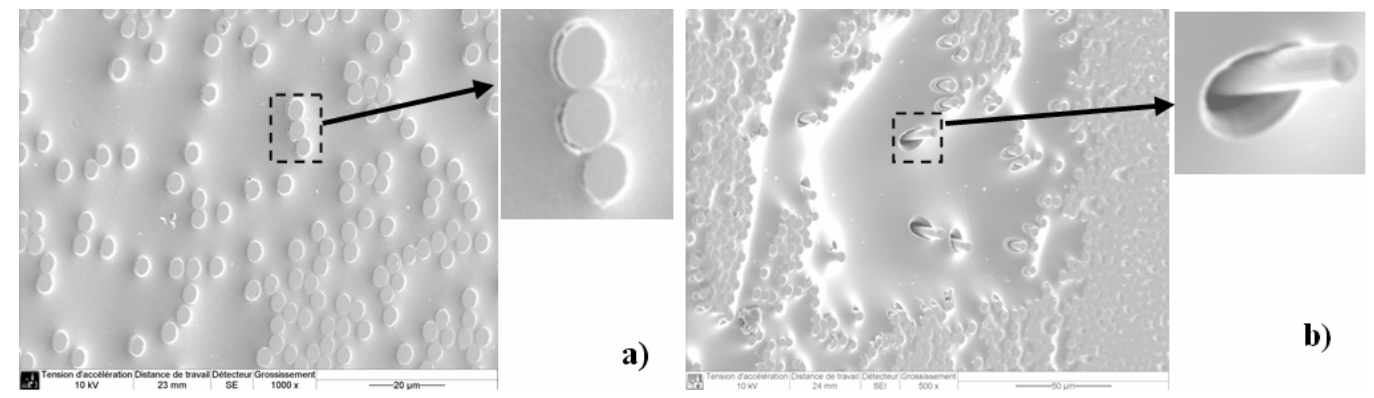

Fig. 8. SEM observations $\left(45^{\circ}\right.$ tilted) of the sample aged isothermally at $150^{\circ} \mathrm{C}$ under 5 bars oxygen (a) $20 \mathrm{~h}$ and (b) $49 \mathrm{~h}$

\section{Conclusions and perspectives}

In this work, we have characterized the thermo oxidation induced matrix shrinkage in a unidirectional $[0]_{40}$ carbon/epoxy composite. Isothermal aging tests at $150{ }^{\circ} \mathrm{C}$ under atmospheric air and under different oxygen pressures ( 1.7 bars and 5 bars) were carried out. It was shown that the matrix shrinkage increases with fibre-to-fibre distance and with oxygen pressure. The dispersion of the experimental points is significant and this dispersion increases with aging time. In fact, this dispersion is due to the difference in the configuration arrangement, for a same fibre-to-fibre distance. SEM observations with very high magnification were used to visualise the matrix shrinkage and the fibre-matrix debonding. It is shown that the onset of fibre-matrix debonding depends on the oxygen pressure and the increasing of oxygen pressure will accelerate the thermo oxidation phenomena by decreasing the time of the fibre-matrix debonding onset.

The results in this work contribute to the understanding of the kinetic of damage. Also, CIM measurements represent a very good data base for the validation of numerical models.

\section{Acknowledgement}

The authors would like to thank Mr. Noël Brunetière (LMS-Poitiers) for his help in performing CIM measurements.

\section{References}

1. Colin X., Marais C. and Verdu J., Polymer Testing, 20 (7): 795-803, (2001).

2. Schieffer A., Maire J.F. and Leveque D., Composites Science and Technology, 62 (4): 543-549, (2002)

3. Lafarie-Frenot M. C., International Journal of Fatigue, 28 (10): 1202-1216, (2006). 
4. Pochiraju K.V., Tandon G.P., Shoeppner G.A., Mechanics of Time dependent Materials, 12: 45$68,(2008)$.

5. L. Olivier, C. Baudet, D. Bertheau, J.-C. Grandidier, M.-C. Lafarie-Frenot, Composites Part A: Applied Science and Manufacturing, 40 (8): 1008-1016, (2009). 